\title{
Diagnosis of cellulitis in patients infected with the human immunodeficiency virus
}

\author{
IRENEO DiaZ MD, SURESH NeELAGaru MS, LAWrence DALl mD
}

\begin{abstract}
I Diaz, S NeElagaru, L Dall. Diagnosis of cellulitis in patients infected with the human immunodeficiency virus. Can $J$ Infect Dis 1994;5(2):84-85. A prospective microbiological evaluation of cellulitis in 22 patients infected with the human immunodeficiency virus was performed. Patients with helper lymphocyte counts of less than 200 cells $/ \mathrm{mm}^{3}$ had a greater frequency of positive cultures. The most frequently isolated pathogens were Staphylococcus aureus and Streptococcus pyogenes, and initial antibiotic therapy should cover these Gram-positive cocci.
\end{abstract}

Key Words: Cellulitis, Human immunodeficiency virus, Needle aspiration culture

\section{Diagnostic de cellulite chez des patients infectés au VIH}

RÉSUMÉ : Une évaluation microbiologique prospective de cas de cellulite chez 22 patients infectés au virus de l'immunodéficience humaine a été effectuée. Les patients dont la numération des lymphocytes auxiliaires était inférieure à 200 présentaient une fréquence plus élevée de cultures positives. Les pathogènes les plus souvent isolés ont été Staphylococcus aureus et Streptococcus pyogenes et une antibiothérapie initiale devrait couvrir ces germes gram-positifs.

$\mathrm{S}$ KIN AND SOFT TISSUE INFECTIONS ACCOUNT FOR UP TO A third of the infections in the immunocompromised host (1). Human immunodeficiency virus (Hrv)-infected patients commonly have cutaneous bacterial infections although the true incidence has never been defined. These infective processes include cellulitis, folliculitis and abscess formation. The usual offending pathogens include Streptococcus pyogenes and Staphylococcus aureus, but other species of streptococci, Gram-negative rods, fungi and mycobacteria have also been reported. Cellulitis has classically been characterized by pain, swelling, erythema, warmth, induration and associated regional adenopathy. There have been several studies examining the diagnostic utility of needle aspiration and tissue biopsy in the etiological diagnosis of cellulitis. Kielhofner et al (2) and Sachs (3) underscored the influence of an underlying compromised host defence in obtaining a positive needle aspiration culture.

\section{PATIENTS AND DESIGN}

Truman Medical Center is a 312-bed primary teaching hospital of the University of Missouri in Kansas City. HIV-positive patients with a clinical diagnosis of cellulitis based on findings of erythema, warmth, swelling, induration and pain were eligible for the study. Fine needle aspiration using a gauge 21 or 22 needle were performed on the leading edge of the cellulitis as described by Ulman and Kunin (4). The samples were inoculated in thioglycolate broth, McConkey agar, chocolate agar, trypticase soy blood agar and colistinnalidixic acid medium. Two sets of blood cultures were drawn from different peripheral vein sites after povid-

Section of Infectious Diseases, Truman Medical Center, University of Missouri-Kansas City School of Medicine, Kansas City, Missouri, USA

Correspondence and reprints: Dr Lawrence Dall, University of Missouri-Kansas City, School of Medicine, 2411 Holmes, Kansas City, Missouri 64108, USA. Telephone (816) 235-1964, Fax (816) 556-3953

Received for publication February 3, 1993. Accepted May 4, 1993 
ine-iodine and alcohol skin preparation. The samples were cultured aerobically and anaerobically using the Bactec system (Becton-Dickinson, Maryland) and held for at least seven days. Statistical analysis was done using Fisher's exact test. A P value of less than 0.05 was deemed significant.

\section{RESULTS}

Twenty-two HIV-infected patients with cellulitis were enrolled in the study over a six-year period. All of the patients were male. Twelve had CD4 (helper lymphocyte) counts of less than 200 cells $/ \mathrm{mm}^{3}$. No neutropenic (counts less than 500 cells $/ \mathrm{mm}^{3}$ ) patients were included in this study. Cellulitis involved the upper extremity in nine patients and the lower extremity in 13 patients.

The blood cultures were positive only in patients with a positive needle aspirate and in whom the organisms were identical. $S$ aureus was the most frequent isolate found in six $(27 \%)$ patients followed by $S$ pyogenes in three (14\%). No opportunistic pathogens were isolated.

The data were analyzed with respect to severity of HIV infection using Fisher's exact test. The patients were divided into two groups based on CD4 counts (greater or less than 200 cells $/ \mathrm{mm}^{3}$ ). Table 1 shows the relationship of CD4 count to the positive yield of needle aspirate and blood cultures. Patients with CD4 counts less than 200 cells $/ \mathrm{mm}^{3}$ were significantly more likely to have a positive blood culture ( $\mathrm{P}=0.015)$. More etiological diagnoses were made by needle aspiration culture in the entire population $(\mathrm{P}=0.05)$.

\section{DISCUSSION}

Previous reports on the utility of needle aspiration of cellulitis have provided conflicting results. In normal hosts, the positive yields range from 10 to $28 \%(5-7)$. Kielhofner et al (2) demonstrated that the presence of an underlying disease process such as diabetes or malignancy significantly increased the yield from this

\section{REFERENCES}

1. Wolfson JS, Sober AJ, Rubin RH. Dermatologic manifestations of infection in the compromised host. Ann Rev Med 1983:34:205-17.

2. Kielhofner MA, Brown B, Dall L. Influence of underlying disease process on the utility of cellulitis needle aspirates. Arch Intern Med 1988;148:2451-2.

3. Sachs MK. The optimum use of needle aspiration in the bacteriologic diagnosis of cellulitis in adults. Arch Intern Med 1990;150:1907-12.

4. Ulman SJ, Kunin CM. Needle aspiration in the diagnosis of soft tissue infections. Arch Intern Med 1975;135:959-62.

5. Hook EW, Hooton TM, Horton CA, et al. Microbiologic evaluation of cutaneous cellulitis in adults. Arch Intern Med 1986;146:295-7.

6. Duvanel T, Auckenthaler R, Rohner P, et al. Quantitative cultures of biopsy specimens from cutaneous cellulitis.
TABLE I

Relationship of CD4 count to needle aspirate and blood culture

\begin{tabular}{|c|c|c|c|}
\hline \multirow[b]{2}{*}{ Procedure } & \multicolumn{2}{|c|}{ CD4 count (cells $/ \mathrm{mm}^{3}$ ) } & \multirow[b]{2}{*}{$P$ value } \\
\hline & $<200$ & $>200$ & \\
\hline Positive needle aspirate & 7 & 2 & \\
\hline Negative needle aspirate & 5 & 8 & $0.09^{*}$ \\
\hline Positive blood culture & 6 & 0 & \\
\hline Negative blood culture & 6 & 10 & $0.015^{*}$ \\
\hline
\end{tabular}

diagnostic procedure. Sachs (3) showed by logistic regression analysis that underlying disease and temperature are the best predictors of positive needle aspiration culture.

There have been no studies evaluating techniques for the microbiological diagnosis of cellulitis in HIVinfected patients. This study shows that cellulitis in HIV patients is due to usual pathogens such as $S$ aureus and $S$ pyogenes. Patients with lower CD4 counts were much more likely to have positive blood cultures, and needle aspiration was a useful diagnostic tool in HIV patients. Kaplan et al (8) noted that most infectious cutaneous complications appear when the CD4 count falls below 100 cells $/ \mathrm{mm}^{3}$. In their series, seven of nine patients with infections caused by $S$ aureus and $S$ pyogenes were seen in patients with decreased CD4 counts.

HIV infection induces profound abnormalities in multiple cell lines involved in the immune response (9). Neutrophil chemotaxis and bactericidal function is likewise impaired (10). The combination of frequent nasal carriage of $S$ aureus (as high as 50\% [11]), an impaired cutaneous barrier and immune defects leads to high rates of $S$ aureus cellulitis in this population.

It seems prudent initially to treat HIV-infected patients with cellulitis with antistaphylococcal therapy and to reserve the use of fine needle aspiration for the patient who is not responding to therapy.

Arch Intern Med 1989;149:293-6.

7. Lutomski DM, Trott AT, Runyon JM, et al. Microbiology of adult cellulitis. J Fam Pract 1988;26:45-8.

8. Kaplan MH, Sadick N, McNutt S, et al. Dermatologic findings and manifestations of acquired immunodeficiency syndrome. J Am Acad Dermatol 1987; 16:485-506.

9. Abramson JS, Mills EL. Depression of neutrophil function induced by viruses and its role in secondary microbial infections. Rev Infect Dis 1988;10:326-41.

10. Rolides E, Mertens S, Eddy J, et al. Impairment of neutrophil chemotactic and bactericidal function in HIV-infected children and partial reversal after in vitro exposure to granulocyte-macrophage colony-stimulating factor. J Pediatr 1990;117:531-40.

11. Berger TG, Obuch ML, Goldschmidt RH. Dermatologic manifestations of HIV infection. AFP 1990;41:1729-39. 


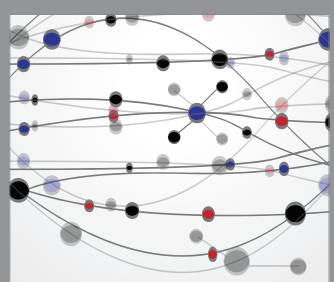

The Scientific World Journal
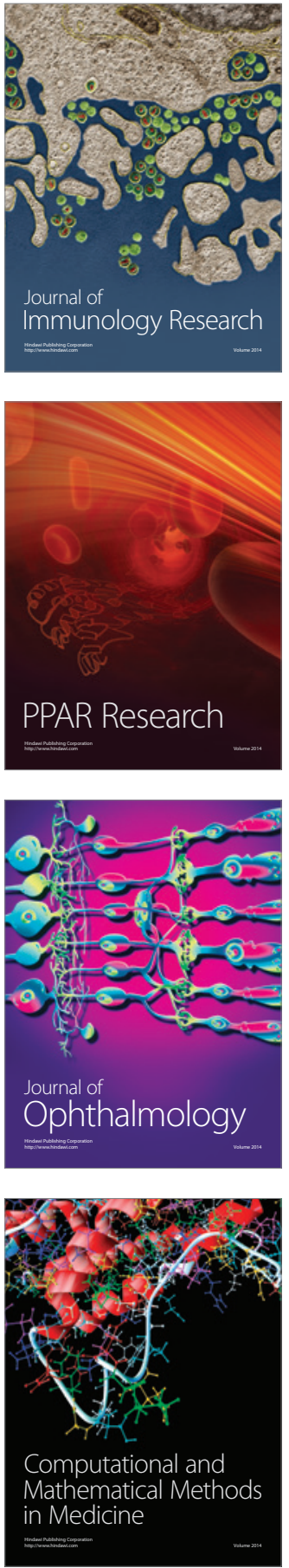

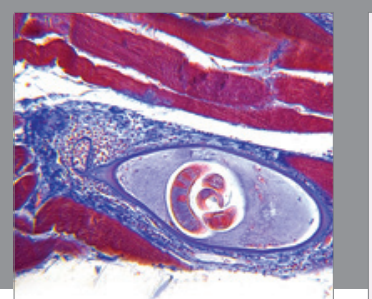

Gastroenterology Research and Practice

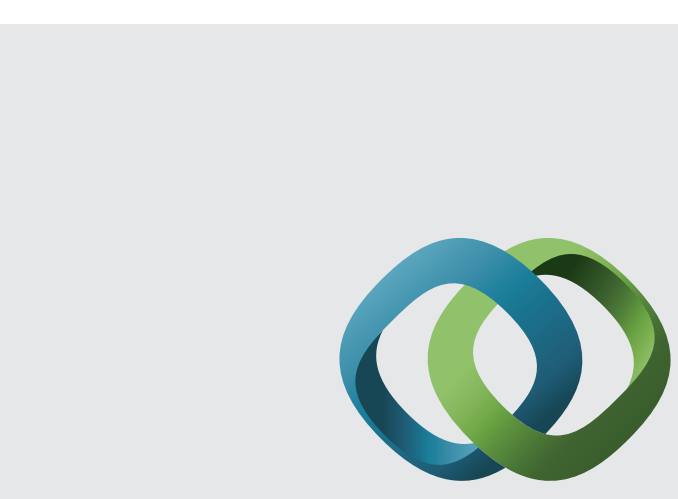

\section{Hindawi}

Submit your manuscripts at

http://www.hindawi.com
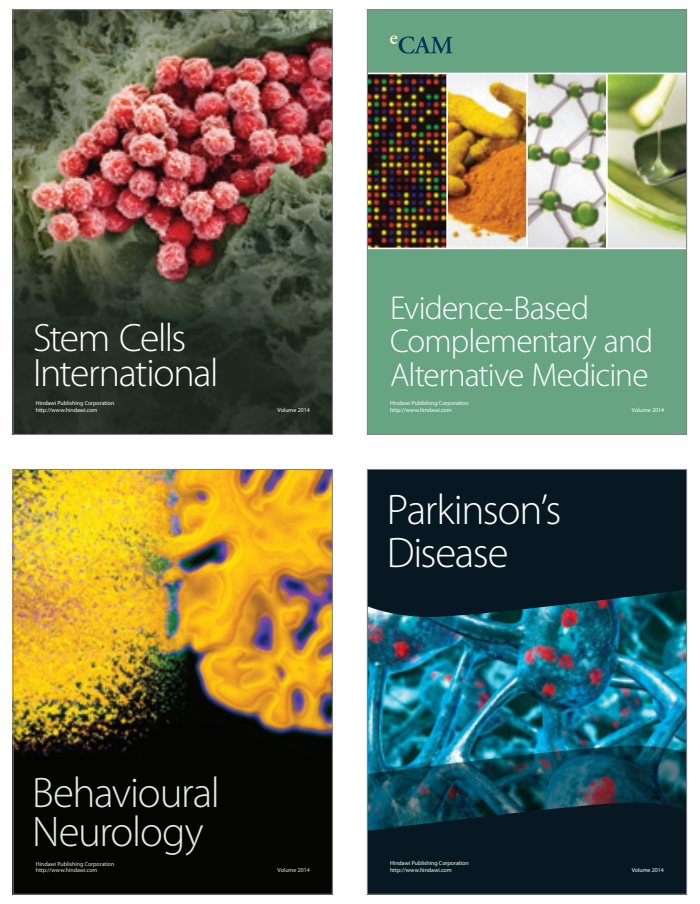
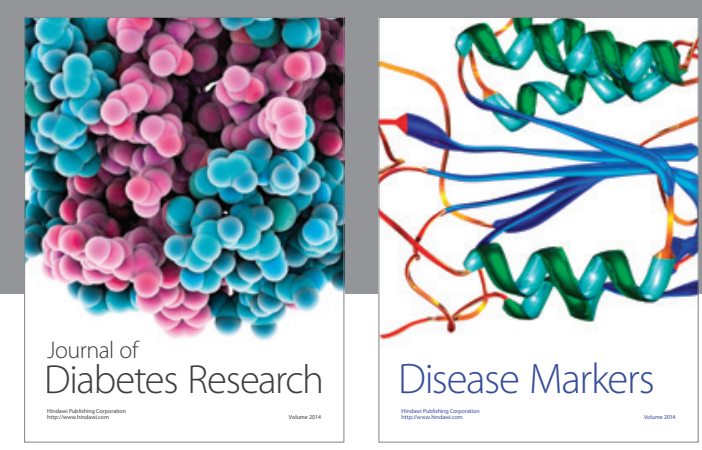

Disease Markers
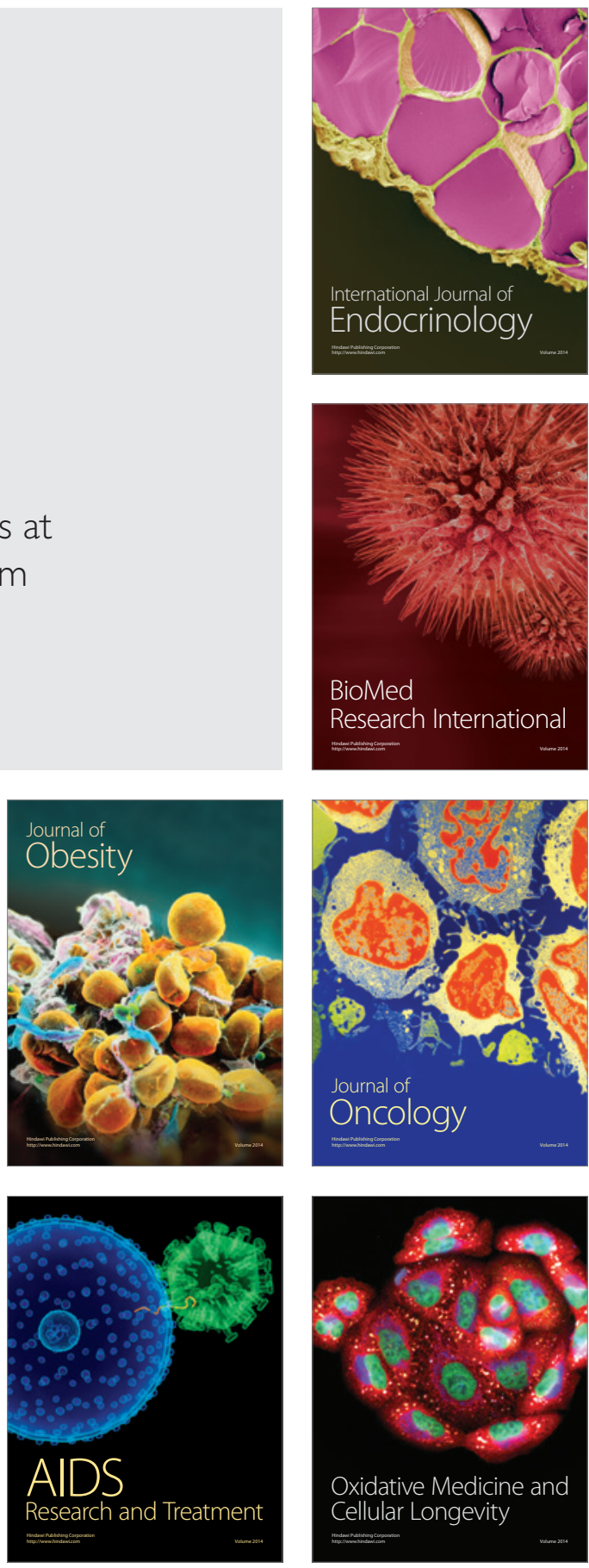